\title{
Exploration on the Ways to Develop Critical Thinking Skills in College English Writing Teaching
}

\author{
Shuli Wang ${ }^{1}$ \\ ${ }^{1}$ Fujian Normal University Minman Science and Technology Institute, Nan-an, Quanzhou, Fujian, \\ China 362332 \\ hunter2011@foxmail.com
}

Keywords: Critical Thinking Skill; College English; Writing Teaching

\begin{abstract}
Writing is the most effective way to cultivate the critical thinking skills of students. Combined critical thinking skills in domestic research with writing teaching practice, this paper discuses the importance of writing and critical thinking skills training, and according to critical thinking skills in accordance with domestic and the international research, this paper describes the specific strategies and speculative writing ability.
\end{abstract}

\section{Introduction}

Over the years, China's college English teaching has always tended to focus on language skills training, lighten thinking ability. Huang Yuan-shen called it as "speculative absence", he pointed out that "the absence of speculative directly affect people's creativity, research capacity and ability to solve problems affecting the quality of people." and in my opinion, it also affects the development of students' interest in learning English as well as their language skills. Critical thinking skill is an important part of the overall quality, is also an important part of the psychological quality. Excellent critical thinking skills show the unique personality perspective and reflect the breadth and depth of thinking.

As a required course, university English courses are in the vast majority position of teaching process and will last for two years. Currently, there are many schools reducing college English class hours, which arouses uproar in foreign language teaching profession, college English courses may be canceled, some people worried about their jobs in the future may not be secure, it was followed by Xia Qi-li, in fact, they first ignored an important theory: the prevalence of language depended largely on whether it was strong in the native language of the country or not. Second, they also ignored another important fact: Currently, the largest number of English-speaking countries, English-speaking countries in terms of economic strength and technological innovation were overwhelmingly dominated. In Western countries, the vast majority of people will again take a foreign language, there may be the need to work, there may be cultivate sentiments. As Chinese people, we should also learn Chinese under the premise of a foreign language. So, at the moment, the United States, Britain, Canada, Australia and other English-speaking countries are still very powerful era in this modern society, it is wise to choose to learn English.

\section{The Situation of Critical Thinking}

2500 years ago, the Buddhist teachings have speculative discussion and research on ancient Greek Socratic questioning the direct authority to determine whether a reasonable point of view also belongs to the speculative category. China has long been "deliberative, discernment". To the modern field of education, American educator John Dewey is the early one to advocate the thinking subject and the "reflective thinking" as a development goal of education. In the late 1980s, Delphi project group (The Delphi Project), put forward the constituent elements of a systematic study of critical thinking skills and critical thinking skills under an authoritative definition: We understand the critical thinking skills as purposeful, self-regulation judgment, which led to evidence category, the concept of class, for class, standard class, class or background factors to consider interpretation, 
analysis, evaluation, reasoning and interpretation, and the determination is built on this foundation. Domestic scholars, such as Wen Qiu-fang, studied the development and application of critical thinking skills test measuring and launched an in-depth study and proposed "level theoretical models." About English extensive reading teaching, Gong Yunhua has taught how to train students' critical thinking skills. Separately from language teaching aspect, Yuan Ping-hua and Qin Bai-su discussed students on how to improve the preparation of the angle. At present, research on critical thinking skills focused on the analysis of English majors reasons for the absence of critical thinking skills, summed up a comprehensive strategy to improve critical thinking skills.

\section{The Reasons of Absence of College English Writing in Critical Thinking}

From an academic point of view, ideology refers to the role of human knowledge stored in the brain ponder with various activities and can feel the existence of life. To be simple, it is the people and things to be understood and viewed by other people. Now the university, can be described as more and more open course, this reason may lay in the rapid development of specialized segments. In a dozen years ago, the total number of four-year undergraduate university courses is about 35, and now the total number of undergraduate university courses is generally around 50 . Despite the large number of courses, the nature of the course do categorize analyze and summarize, we find that there are only about $80 \%$ of which are knowledge-based or skills-based courses, but the ideological course students loved is much rare. Little analysis can you learn from this and a lot of people in recent years, advocate the supremacy of pragmatism and efficiency are not unrelated. Put it more bluntly, from the outset and inset our education has been put most of the focus on the intelligence education, and the importance of emotional intelligence education is extremely lacking. Right now, from kindergarten to primary school, a variety of training courses had been flooded. For example, a 3-year old kindergarten child in small class has three courses at least, for English, his young childhood already lost the enjoyment of this childlike, and we have to say this is a kind of sadness. Learning is not wrong, but the adults' thinking that is used in adults has deprived the child's imagination and repressed their childhood passion and it is the sinner of the order. Many children in kindergarten or elementary school are already busy in poetry and painting, but the meaning to learn so much at present age is still unknown. It is the parents' hearts comparisons of dictates, which has not understand the consequences of education, which will contribute to a more profit-oriented and pragmatic unhealthy.

On teaching objectives, each course is different. However, the nature of the teaching objectives to classify, each course has its explicit and implicit teaching objectives for teaching goals. Only if teaching objectives have explicit or teachers achieved its explicit teaching goals, teaching a course is meaningful, and then we can say that the teaching of the course is targeting biased or that there is much room for improvement of the teacher's teaching level. On explicit teaching objectives, the presentation of each course varies. However, with implicit teaching objectives, each course has a great similarity. Especially for the critical thinking skills of students in ideology, they are subject to full attention. In China, college students who have to enhance critical thinking skills have become one of the important goals of higher education.

So, what is speculative capacity? It is said that: "Erudite, interrogated, deliberation, discernment, persistent work." This is the sentence of a famous educator, but one of the "thinking" and "identified" is also important for life and work, it is also a source of speculative sentence. Speculation is a complex, comprehensive high-level mental activity, including analysis, reasoning, judgment and other thought of the activities. Speculation refers to the ability of the individual in accordance with a particular standard, before things or phenomena judgment making decisions or conclusions of mental activity, including the question of reasoning, independent thinking, analysis and evaluation capabilities.

Language and culture are two-way interaction. Writing on the one hand should take into account the role of social norms and create a culture of language. On the other hand writing is a continuous cycle of cognitive process, which includes the idea of creating and modifying text, but also includes 
the social environment and personal emotional constraints and other factors. Thus, writing ability will affect the family social, cultural, second language teaching methods and other factors.

First, the cultural circle concept is inherent form understanding of the constraints. Chinese traditional culture restricts the student's way of thinking cognition and thinking, Chinese college students are often easy to walk into saints authoritative knowledge is immutable misunderstanding. Atkinson believes that speculative thinking mainstream benefits from Western culture, because the ability to contain speculative individualism, self-expression, language and cultural traditions has been taken as a learning tool. Oriental culture is used to pursue cultural ideas of collectivism, the inherent cultural traditions habits directly affect classroom teaching, in rarely times do Chinese students in the classroom are taught and guided by teachers, or even completely subordinated to the teachers.

Secondly, the essential characteristics of English writing are also bound to improve critical capacities. On the one hand, writing requirements of English language learners have a solid language foundation and careful logical thinking ability; on the other hand, writing is language learners' ability to build social culture. Now the English classroom learning around knowledge transfer was often excessive mechanical language practice, and less really inspired students to speculative discussions and presentations. When writing training starts, most students have always a certain fear, worry that the language skills need to keep up with the expression, on the other hand, the topic given by teachers has too much thought limitations because the problem itself is not profound understanding of the cause without their own ideas and opinions in the composition.

In addition, English writing teaching methods can be used to improve the ability with restrict speculative. In the teaching of writing, teachers are often exam-oriented, require students to practice writing once into the draft, focus on language fluency and accuracy of the content itself, lack of communication and cooperation between students, between teachers.

\section{The Strategies to Cultivate Critical Thinking in College English Writing}

On foreign language teaching, the students' critical thinking skills should also be one of its main teaching objectives. Relationship between language and thinking is extremely tight and therefore, language learning can be used for dependence thinking self-evident. In turn, the level of critical thinking skills will largely affect language learning. Foreign Language Teaching and critical thinking skills can be said to be a complementary relationship and stay in harmony, these two has been isolated and completely set aside the critical thinking skills of foreign language teaching. Both of these are misguided, less effective, and doomed to failure.

As a college English teacher, we should consider the level of students' critical thinking skills for language learning have extremely important implications. Now, teaching students to do reading comprehension, cloze, translation, writing and other topics are extremely important. How many times have you angry because of students' speculative weak and ridiculous? In fact, students' falling in wrong topic is largely due to their critical thinking skills and is not due to language proficiency. Sometimes you will find that even if you put the reading comprehension sentences translate into Chinese, many students still two dazed and incomprehensible. Is it because the students can not explain speculative weak and affect their language study? Therefore, college English teachers should teach students the language skills and cultural knowledge, while paying attention to enhance students' critical thinking skills.

Whether reading and writing, listening and speaking course, translated lesson or reading lessons, teachers can put language teaching and training students' critical thinking skills combine. Take the reading and writing for example, many teachers believe that the text is nothing to talk about, or feel very boring to explain the text, it is not the truth. College English reading and writing classes are just like English professional intensive reading course, it is like high school students attending a language lesson, teacher can put background information texts, videos, text grammar, ideological and cultural connotation of content together in terms of ideology and those can lead students to travel in the text. Discussion describes the background, video viewing, succinctly, opinions, comparative culture and knowledge combined with life extension of critical thinking skills, students 
will be of great benefit to join in all of those. In particular, to explain the text and grammar of the text, it is the test of a teacher with language skills, cultural literacy, critical thinking skills and knowledge structure. In addition, teachers explain the text, but also may be the right time to jump off in some texts, combine with teachers' personal experiences or examples around the students appropriately extended, sometimes even speak some inherent philosophical joke, which both inspire students interest in learning and ignite their passion for learning, but also in terms of ideology and students' interaction can guide them the right to look at things around, to enhance their capacity for critical thought.

If the student's critical thinking skills have been improved, their understanding of the language and learning will naturally be more smoothly and college English teaching also will get a multiplier effect. Previously, students do not understand or are not interested in them and the teacher does not lead to interaction. Now, students' critical thinking skills have been gradually improved, and the teacher's interaction increases, interests in the passion are ignited, the learning effect will be leaps and bounds. This is the result of students' critical thinking skills upgrading, is the best embodiment of college English teaching objectives implicit reached.

Broaden their Cultural Horizons and Cultivate the Habit of Independent Thinking. Language is the carrier of culture, it is a tool for cultural dissemination. Language is also a tool for thinking. As a tool for thinking, language, to some extent, restricts the way of thinking, the scope and depth. Learning the English language can not be confined rigidly in memorizing vocabulary, pronunciation, grammar, but to improve the language skills and cultural acquisition and to develop thinking on the basis of overseas ideas. Thus, when the students learn a language, we cannot ignore the culture of understanding and knowledge, particularly the cultural circle of people to understand the way of thinking. In order to truly grasp the nature of language learning, the only way is to achieve the language and culture of "two-pronged" and thinking.

Optimization of the Process of Teaching Writing. Professor Yang Yonglin pointed out: Writing is not only to solve the "how to write" problem, but also to focus on "how to think" the critical thinking training. Writing in the prominent contradictions of thinking is how to inspire students. Traditional writing teachers often emphasis on technical writing too much, for example, whether there is a content of the point of writing, grammar, fluency of expression right, and the writing process for students rarely intervene to lead students to improve logical thinking ability and innovation ability, the ability to independently analyze and solve problems cannot be formed. 1970s, Western scholars propose process approach (process approach) which emphasizes that writing is a complex process that is higher mental cognition and communicative language combination. The method of preparation before the writing into writing, writing and rewriting includes three stages. This method helps interaction and communication between teachers and students and to develop students' thinking skills.

The method to solve problems is an important way to improve the critical capacities. Speculative writing ability is the choice of topics including writing, writing content selection, discussing and the evaluation of logical structure results. Writing question should be raised on student selective interpretation of the problem itself, it is concerned about the natural world and human world. William \& Barron stressed that the most appropriate topic should be really interested in students, not in the teacher assigning homework. Once the topic of writing is discussing, it is not a conclusion, but the formation of judgment, teachers and students are around the topic of selecting the relevant information, building writing outline, trying to figure out effective consultation linguistic expressions. For example, the main material for the promotion of students to deepen thinking, teachers need to design a list of questions to facilitate students in reading material specific targets. Teachers can help students to form opinions for sources of information. It helps students from passive learners into active learners, and stimulates interest in learning. After perfecting writing material, teachers and students can dialogue, panelists and other forms of writing logic to sort out. Students' cognitive ability, revitalize existing knowledge and has benefitted from exploring new knowledge. Traditional writing summative evaluation is that students' writing gives an overall judgment and evaluation, emphasizes on accuracy and the ability to structure and organization of 
the student's language and responds to CET, it should not be written for students' processes, methods and attitudes assessed. Formative assessment is equivalent to the portfolio assessment. (Portfolio Assessment) is the original evaluation methods of improvement, it is more emphasis on the writing process, the writing process has students' psychological, emotional factor such as record, improves analysis ability of students, the depth and breadth of reasoning and evaluation capacity and knowledge of writing. By recording the discussions, Students can talk about ideas and reflection process and this helps to obtain timely feedback from peers and teachers; In order to adjust the teaching schedule, teaching content and methods, teachers with reviewers (including student peer assessment and self-assessment content) can also pay more attention to students' learning behavior, learning motivation and strategy changes

Improve Teaching Concepts and Speculative Consciousness. Teachers must first realize the importance of developing students' critical thinking skills, and change the original pattern inherent to the classroom and teach analytical essay writing rules, expand critical thinking skills for students to explore. Writing in the classroom, teachers should try to use the issue to inspire students to expand positive thinking, to carry out research for a social hot spot and youth concerns, and gradually develop students' independent thinking, analysis and problem-solving skills.

\section{Conclusion}

Writing is one of the most effective ways to develop students' critical capacities. We should rethink the whole process of teaching, writing, teaching objectives, methods and evaluation methods from a speculative point of view. Teachers themselves must recognize the importance of critical thinking skills on training and take efforts to explore ways to improve speculative ability.

\section{References}

[1] HuangYuan S. Study on Speculative Absence of Foreign Language Teaching. Foreign Language and Foreign Language Teaching, 1998(7).

[2] WenQiu F. WangJian Q. A Conceptual Framework for Assessing Chinese college Students' Critical Thinking Skills. Foreign Language World, 2009 (1).

[3] QianKun Q. Foreign Acquisition and Critical Thinking Skills, Language Teaching, 1996 (3).

[4] YuLi M, YuanDu P. Bilingual Teaching and College English Teaching. Higher Education Research; 2005 (3). 